PerkinElmer, Mikrouna, IKA, Huber, and Springer. With their generous contribution, nice conference services were provided, such as free buffet for lunch and supper, free poster print service, free take/delivery service, and cash award for the poster and youth forum winners, etc. To alleviate the discomfort of delegates caused by the language difference, 20 volunteers with good English communication abilities were recruited. Four Journals acted as the academic sponsors, they will issue special issues for this conference; they are Journal of Salt Lake Research (Pre-Conference, English edition has been published, http://yhyj.ijournal.cn/ch/reader/ issue_list.aspx?year_id=2019\&quarter_id=2), Pure and Applied Chemistry, Journal of Solution Chemistry, and Computer and Applied Chemistry (Post-Conference).

Thus, ICSC2019 was successful on several fronts: high-quality science, interesting social programs, and nice conference services.

Special thanks go to the Chinese Chemical Society Subcommittee on Thermodynamics and Thermal Analysis (especially Jianji Wang and Zhiwu Yu).

Special thanks also go to the organisers from the QISLCAS (especially Changling Zhao, Hongen Nian, and Jingjing $\mathrm{Li}$ ) and Tianjin University of Science and Technology (especially Tianlong Deng, the co-chairman of ICSC2019) and to the contributing members of the Solution Structure Research Group at QISLCAS: Dengke Pang, Guangguo Wang, and Zhuanfang Jing.

ICSC looks forward to meeting again in Cartagena in 2021 !

Yongquan Zhou (Roger), Secretary-General of the 36ICSC Local Organizing Committe Qinghai Institute of Salt Lakes, Chinese Academy Of Sciences

\section{Flying Chemistry Educator Program in Ulang Bataar, Mongolia}

by Jan Apotheker, Anna Marakova, Aurelia Visa

Masahiro Kamata, a long time Titular Member of the IUPAC Committee on Chemistry Education (CCE), visited Mongolia regularly since 2006, to advise school teachers. He used his contacts to initiate the negotiations to organize both a "Young Ambassadors for Chemistry" as well as a "Flying Chemistry Educator Program" (FCEP) at the University of Mongolia in Ulang Bataar from 17-22 September 2019. Ochirhuyay Bayanjargal, vice president of the University, worked together with CCE to organize the FCEP. 28 lecturers from the University, 27 secondary school teachers and 17 researchers from different institutions participated in the event. For IUPAC, two members from the
Interdivisional Committee on Green Chemistry for Sustainable Development (ICGCSD), Anna Marakova and Aurelia Visa were presented and Jan Apotheker, MeiHung Chiu, and Masahiro Kamata represented CCE. The project was financed jointly by ICGCSD and CCE.

The focus of the three-day program of the FCEP was development of Green Chemistry in Mongolia. The university wanted to start a course in Green Chemistry; the secondary school teachers wanted to start a module about Green Chemistry; the researchers were interested in starting research in Green Chemistry. It was an ambitious program for a three-day session.

After the introductions and welcome by Bayanjargal, Jan Apotheker introduced IUPAC, as well as the International Year of the Periodic Table.

Anna Makarova made a short presentation on the topic "What is Green Chemistry?". As part of this lecture, participants were given a definition of Green Chemistry and 12 basic Green Chemistry principles. Discussion the role Green Chemistry in implementation UN Sustainable Development Goals (2015) and its role in observing planetary boundaries. UN Environment (Global Chemicals Outlook II) [1] data were presented for the market size of the global green chemistry industry (2015-2020) and the global green chemicals market by region (2011-2020), of which the Asia-Pacific region have more than $30 \%$.

After her presentation Makarova organized a discussion framing the possible advantages of introducing Green Chemistry as well as a possible strategy (main activities) of the development of Green Chemistry in Mongolia. The VISIS method and technology "Pyramid" developed by Atkisson and others was used [2] for clarity and visualization of the discussion. The VISIS method takes it name from its five stages:

Vision and goals: In this case, the main goals of the object of research were the creation of courses and training modules as well as the organization of research projects in the field of green chemistry.

Indicators: This stage includes analysis of available data on the effects of the object of research on environmental, economic, societal and individual well-being dimensions, and identifying current trends.

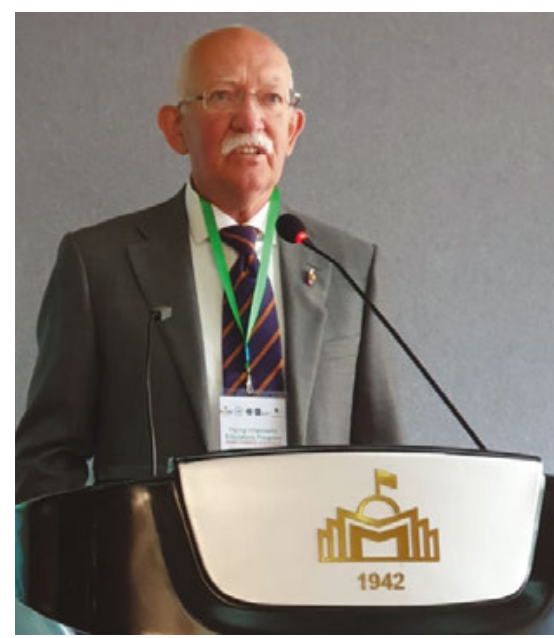

Jan Apotheker introducing IUPAC 
these values do not account for pollution, the use of solvents and the resulting wastes have been reviewed in other values for measuring the green degree of the reaction. Thus, various metrics such as atom economy, e-factor, atom efficiency, effective mass yields, process mass intensity, carbon economy, SWOT analysis, and life cycle assessment were introduced.

Many of the principles of Green Chemistry can be applied in everyday life, such as waste prevention or more energy efficient industrial processes on a large scale to minimize waste and reduce environmental impact. Everyone is paying attention to pollution and how to reduce the impact of human activities on climate change.

At the end of the first day the participants visited the laboratories of the University. Sarangarel Davaasambuu, dean of the faculty, discussing chemistry related industries in Mongolia, started of the second day. These are mostly related to mining. $30 \%$ of the GDP of Mongolia is related to mining, at the moment mainly coal and copper. There are other deposits of metals, including uranium and gold. These are mostly exported as fairly raw material to China. The other main source of income is agriculture. Mongolia has a vast area of steppe on which cattle, cow, horse and sheep are held.

Meat is exported. A specific local product, which needs an acquired taste is ayrak, a fermented horse milk. One of the major problems she reported was the lack of adequate management of chemical waste, resulting in pollution both of water and the environment.
In a short presentation about a number of chemical disasters, Aurelia Visa demonstrated the need for Green Chemistry. She also introduced some of the areas of research in Green Chemistry, focusing on reduction of waste and raising atom efficiency, as well as the use of solvents that are not detrimental for the environment. Finding different pathways for reactions, the use of catalysts optimizing atomic efficiency were some of the aspects discussed. Finding alternatives for solvents in the form of super critical liquids was another issue presented.

Before lunch Jan Apotheker gave an introduction about education. Starting with the introduction of the ideas of Piaget and Vygotsky, the framework for the design of a course was presented, based on the model of educational reconstruction (Duit, Gropengießer, Kattmann, Komorek, \& Parchmann, 2012).

The idea is that scientific content is related to research on teaching and learning, for the design of the teaching and learning activities in a course.

For the design of the course the framework of constructive alignment (Biggs, 1996) was used. Based on the learning goals, learning and teaching activities are developed for the course. Based on these same learning goals assessment is designed, directly linked to the teaching and learning activities.

The group was first asked to formulate a more general learning goal for the course. It should express in one sentence the goal of the course. Subsequently the learning goals should be formulated in a more detailed

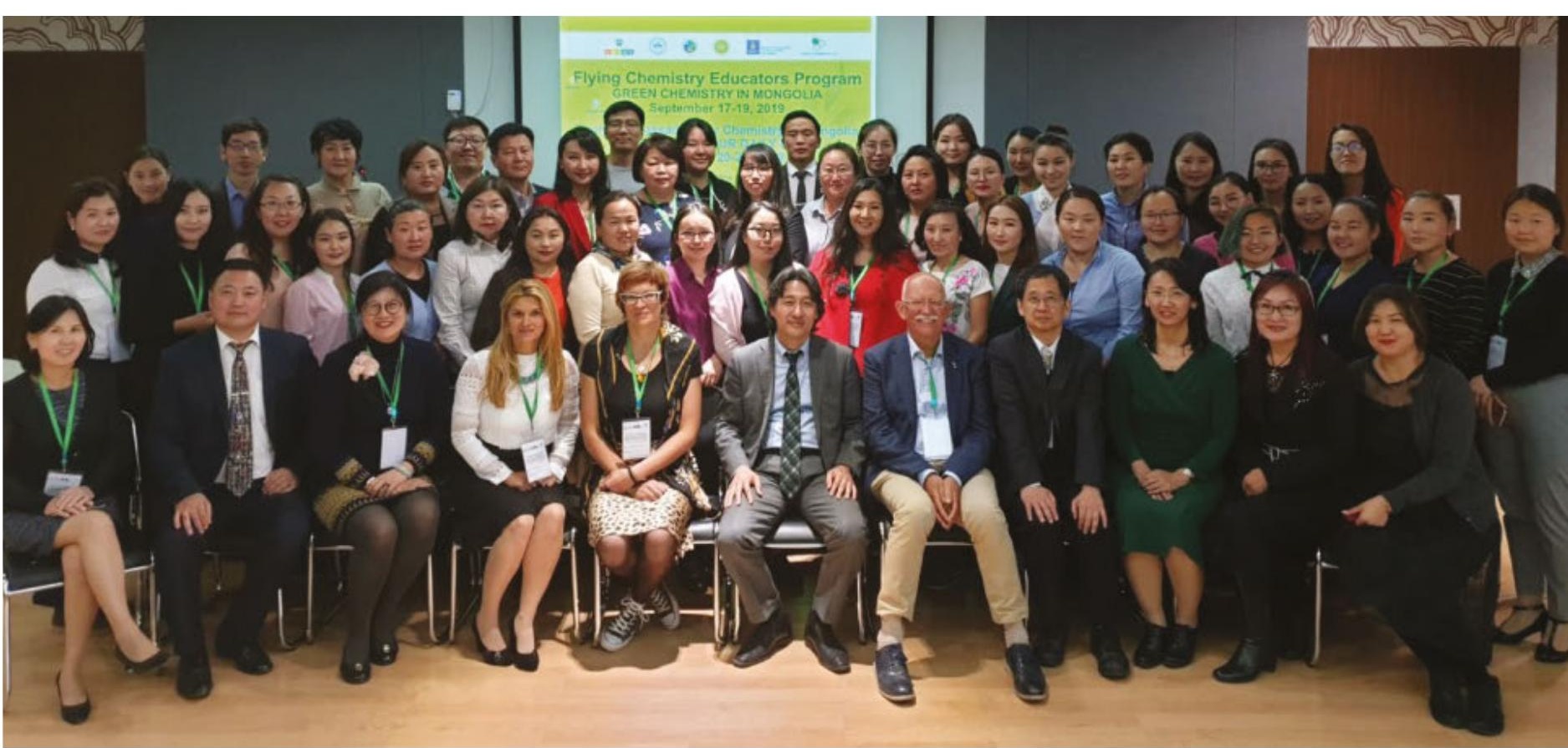


way. These goals should be formulated SMART:

Specific

Measurable

Attainable

Relevant

Timely

\section{Higher education group}

Two groups of about 8 members of university faculty worked on the design of a course, which were partly overlapping. They intend the course to be placed in the end of the third year. Interesting was that in one of the groups a lab session was envisioned, in which students are asked to design alternative pathways for a synthesis, which are as green as possible. In the subsequent steps they were asked to design a waste management for the waste produced during the reaction, so that the waste can be reused.

They were also asked to introduce formative assessment in the lecture design. At the end of the three day session they are in a position to merge the two proposals into one. It should be possible to introduce the new course in the next academic year.

\section{Secondary education group}

Ultimately two groups worked on a module for secondary education. One was planned for grade 10, the other for grade 9 . The first group ( $9^{\text {th }}$ grade) took drinking water as a subject. Using the 5E framework (Bybee et al., 2006) in which the educational activities are sequenced in 5 steps:

Engage, Explore, Explain, Elaborate, and Evaluate. A sixth $E$ was introduced between Elaborate and Evaluate: Exchange, making it a $6 \mathrm{E}$ model. The Exchange part lets the students share their results with others, either their peers or their parents; we suggested that the students should make an exhibit that can be exposed in the science centre the University is planning to construct in one of their buildings.

The water demonstrates one of the features of Green Chemistry: a cycle. After purification the water is used in the household, and is returned via a waste water plant to the surface water, which is used as a source for the drinking water.

The other module for $10^{\text {th }}$ grade has batteries as a subject and looks into the differences between alkaline batteries and lithium batteries. Again here, a feature of Green Chemistry is introduced, the difference between a cradle to grave design for the alkaline batteries and a cradle to cradle design for the lithium batteries.

Both designs still need some work before they can be tried out in the classroom. We have asked the

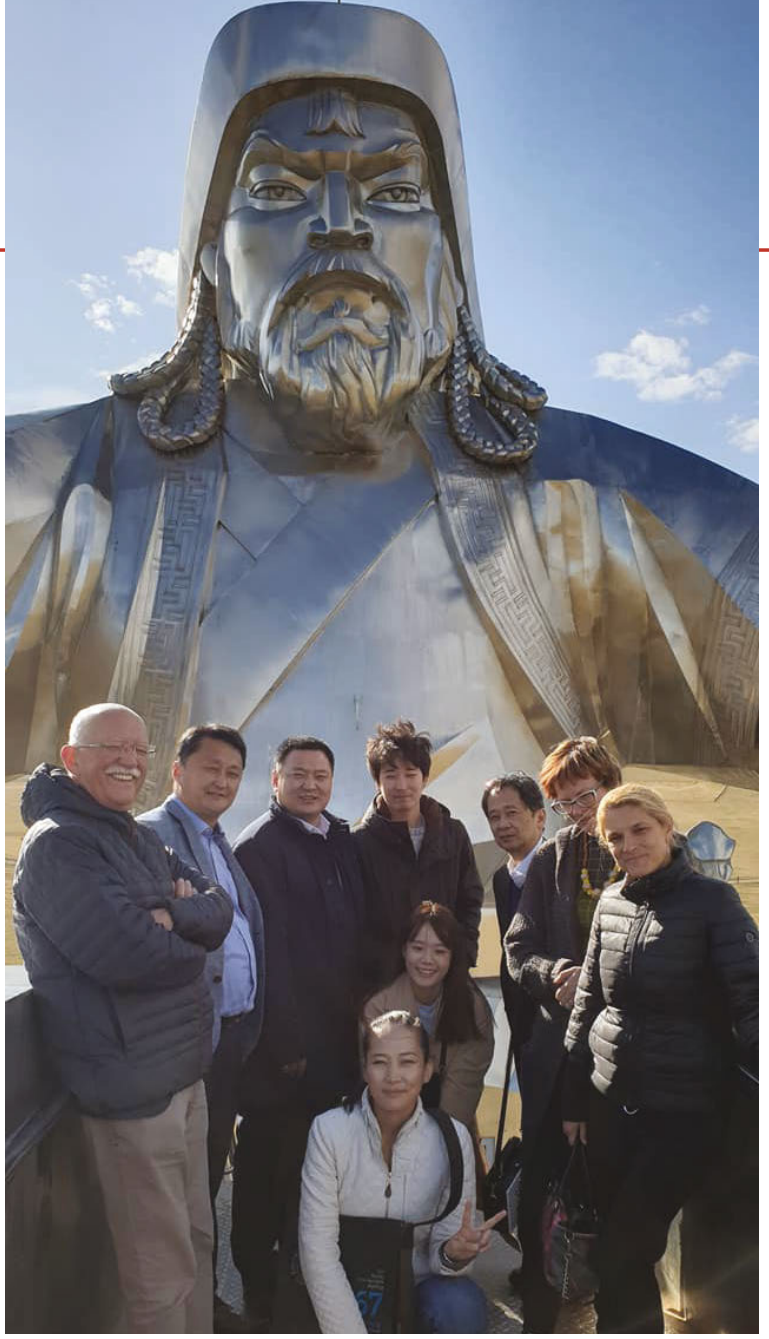

Attendees pose with a stainless steel statue of Ghengis Kahn

University to invite the group of teachers back to the university so they can keep on working together on the design of the module.

\section{Research group}

Anna Marakova and Aurelia Visa coached the research group. They started out with formulating ideas, performing a SWOT-analysis on the suggestions, and came up with a time line for research project. This project should, over a period of three years, lead to the construction of a reactor in which reactions in super critical water can be carried out. Ultimately they want to use this to introduce the use of super critical water into industry.

The research group with participants from different institutions, will continue to work on the proposal, which will be sent in to the Mongolian Science Foundation for financial support. The participants felt they had achieved first steps towards their objectives and will continue to work on their projects. Over time we will contact the university to find out how things have progressed.

\section{Mongolian Chemical Society}

During the three days we had a lunch with the chair of the Mongolian Chemical Society, Avid Budeebazar. He expressed an interest in joining IUPAC as an NAO. 


\section{Acknowledgments}

The FCEP was made possible by the financial support of Green Chemistry LLC and the National University of Mongolia, as well as ICGCSD and CCE from IUPAC. During the week we had work lunches and dinners with several representatives from companies and institutions in Ulang Bataar, like the New Mongol Institute of Technology, The German Mongolian Institute for Resources and Technology, Synaps and Green Chemistry LLC. The last two are both companies trading in laboratory glassware and chemicals.

As a delegation we were fortunate to be able to meet Ghengis Kahn.

\section{Aurelia Visa is senior researcher at "Coriolan Drăgulescu" Institute of} Chemistry, Timișoara, Romania.

\section{References}

1. https://wedocs.unep.org/handle/20.500.11822/ 27651?show=full

2. Atkisson A. The Sustainability Transformation. How to Accelerate Positive Change in Challenging Times. Published November 19th 2010 by Earthscan Publications. P. 323. ISBN 1849712441

3. Prat D., Hayler J., Wells A., Green Chem., 2014, 16(10) 4546-4551).

4. Tundo P., Pure App/ Chem, 2012, 83(3), 411-423

\section{Innovative Chemistry for Environmental Enhancement}

by Diane Purchase, Wenlin Chen, Hemda Garelick, Nadia G. Kandile, Rai Kookana, Bradley Miller, and Roberto Terzano

The IUPAC $47^{\text {th }}$ World Chemistry Congress (Paris, 5-12 July 2019) celebrated the 100 years of IUPAC and the 150th anniversary of the Periodic Table of Chemical Elements. The congress showcased how chemistry addresses today's most challenging issues relevant to human well-being and sustainable development. The Chemistry and the Environment Division of IUPAC (Division $\mathrm{VI}$ ) has sponsored and organized a symposium highlighting the role of innovative chemistry in: a) endof-pipe solutions for industrial processes; b) technologies for pollution and wastes reduction and control; and c) approaches to tackle global environmental challenges. Additional financial support was provided by IUPAC under the 'New Directions in Chemistry' initiative.

Increasing global economic competitiveness, social inequalities and the dimension of environmental problems have raised awareness of the need to change the technological paradigm and challenge the technological status quo. Environmental innovations are essential in reducing environmental impacts and resolving the environment vs. economy dilemma, and chemistry has a significant role underpinning these innovations. Environmental innovations can be achieved via a combination of inputs, such as raw materials, energy and labour. These innovations may be specifically developed to mitigate a specific environmental adverse effect, for instance, in response to regulations; or their benefit is the result of the environmental components of other types of innovations.

The symposia took place over two days (10-11 July), during which a number of high-profile international speakers presented on three special sessions:

- Innovative chemistry in industrial solutions

- Advanced techniques for pollution and waste reduction

- Novel approaches to tackle global environmental challenges

All three sessions were well-attended and well-received, raising awareness of the important topics associated with the work and expertise of Division VI membership. They also provided the opportunity to address specific regional problems and expand current, mainly EU and US based networks.

\section{Innovative chemistry in industrial solutions}

This session celebrated the key role of chemistry in providing innovative solutions to a number of industrial processes to overcome pre-existing challenges, including regulation compliance, carbon footprint reduction, waste and energy consumption minimisation, performance enhancement and sustainability attainment. Life Cycle Analysis (LCA) has already been applied to support different decision-making procedures in product lifecycle management, such as eco-design, process optimizations, supply-chain management, and marketing or strategic decisions.

Our keynote speaker, Anne Gaffney, is the Chief Science Officer and Distinguished Fellow at Idaho National Laboratory, USA. She has worked in industry inventing and commercializing new technologies for major chemical manufacturing companies including Koch Industries, Lummus Technology, Dow, Dupont and ARCO Chemical Company. Gaffney provided a valuable insight into the commercialization of technologies that can transform carbon waste streams into products at a reasonable cost and a net lifecycle reduction of greenhouse gas emissions to the atmosphere. Carbon utilization is based on the notion that waste carbon 